\title{
A cobertura jornalística de fronteiriços e favelados - narrativas securitárias e imunização contra a diferença
}

\author{
Ada Cristina Machado da Silveira*
}

\section{Resumo}

Este artigo realiza uma abordagem da imunização frente à diferença produzida pela cobertura jornalística sobre acontecimentos ocorridos nas periferias pertinentes às fronteiras internacionais brasileiras (fronteiras) e aquelas localizadas em suas áreas metropolitanas (favelas). A opção metodológica que a sociossemiótica aporta permite a análise da cobertura de acontecimentos realizada pela mídia local, por meio de um corpus criado a partir de edições dos anos 2006-2007 de um diário fronteiriço, em contraste com a análise de dois semanários nacionais no mesmo período. $\mathrm{O}$ objetivo geral procurou conhecer a especificidade que o nível local concede aos acontecimentos já estandardizados pela mídia nacional. Os resultados apontam a consistência da hipótese de que o agenciamento jornalístico mantém a noticiabilidade sobre as periferias numa condição discursiva ambígua e que responde por seu enquadramento como alarmes de incêndio, convertendo-as em patrimônio territorial do Estado-nação.

Palavras chave: Jornalismo. Periferia. Fronteiras. Estado-nação. Identidade Nacional.

\section{Borders and favelados journalistic coverage - Security related narratives and immunization against difference} Abstract

The article discusses the immunization perspective against difference produced by Brazilian journalistic coverage about events occurred in peripheries of Bra-

\footnotetext{
* Professora dos programas de pós-graduação de Comunicação e de Extensão Rural, Departamento de Ciências da Comunicação da Universidade Federal de Santa Maria (UFSM) - Santa Maria, RS, Brasil. Pesquisadora do CNPq. Magister em Ciências da Comunicação e Doutora em Jornalismo pela Universidade Autônoma de Barcelona. Jornalista. Mestre em Extensão Rural pela UFSM. Autora de vários artigos, livros e capítulos, destacando-se o livro "O Espírito da Cavalaria e suas representações midiáticas" (Unijuí, 2003).

E-mail: adac.machadosilveira@gmail.com.
} 
zilian international borders (fronteiras) and in its metropolitan areas (favelas). The methodological option that sociossemiotics brings allows the analysis of coverage of events conducted by local media, by a corpus created from editions of 2006 and 2007 of a frontier daily newspaper, in contrast with the analysis of two weekly national newspapers of the same period. The mainly objective was to understand the specificity that local level concedes to events alreadystandardized by national media. Results point to the consistency of the hypothesis that journalistic agency keeps news about peripheries in an ambiguous discursive condition and that responds by its framework as fire alarms, converting them into territorial patrimony of National State.

Keywords: Journalism. Periphery. Borders. National State. National Identity.

\section{La cobertura periodística de fronterizos y favelados - Narrativas securitarias e inmunización en contra de la diferencia \\ Resumen}

El artículo hace un abordaje de la perspectiva de inmunización frente a la diferencia que se produce por la labor de la cobertura periodística en las narrativas a cerca de acontecimientos ocurridos en sus periferias pertinentes a sus fronteras internacionales y aquellas ubicadas en sus áreas metropolitanas. La opción metodológica que la socio-semiótica aporta permite el análisis de la cobertura de acontecimientos realizada por un medio local, a través de un corpus creado a partir de ediciones de los años 2006-7 de un diario fronterizo, en contraste con el análisis de dos magazines semanales nacionales del mismo periodo. El objetivo general procuró conocer la especificidad que el nivel local concede a los acontecimientos ya empadronados por los medios nacionales. Los resultados apuntan hacia la consistencia de la hipótesis de que el agenciamiento periodístico mantiene la noticiabilidad sobre las periferias en una condición discursiva ambigua y que responde por su encuadre en tanto que alarmas de incendio, convirtiéndolas en patrimonio territorial del Estado Nación.

Palabras clave: Periodismo. Periferia. Fronteras. Estado-nación. Identidad Nacional.

\section{Introdução}

A análise da cobertura jornalística sobre acontecimentos ocorridos nas periferias pertinentes às fronteiras internacionais brasileiras e aquelas localizadas nas áreas metropolitanas apresenta uma notável continuidade de enquadramento discursivo. ${ }^{1}$

\footnotetext{
${ }^{1}$ Uma versão anterior do presente artigo foi comunicada no XXIV Congresso da Intercom, no GT políticas e Estratégias de Comunicação. Agradeço aos presentes pelos comentários e sugestões em parte incorporados à esta versão.
} 
$\mathrm{O}$ artigo registra aspectos de um subprojeto do projeto denominado "Brasil, mostra tua cara. A ambivalência de fronteiras e favelas na cobertura jornalística", detido em investigar como a reconstrução sociossemiótica pode ajudar na compreensão da questão da ambivalência significacional. ${ }^{2} \mathrm{O}$ projeto tem como hipótese de trabalho que o agenciamento jornalístico mantém a noticiabilidade sobre as periferias numa condição discursiva ambígua, a qual proporciona enquadrar seus acontecimentos no que viemos a interpretar como alarmes de incêndio que alertam continuamente a comunidade nacional/local para seus perigos.

A metáfora dos sinais de alarme de incêndio (fire alarms signals) provém de McCubbins e Schwartz (1984) quando tratam dos procedimentos utilizados para vigiar e controlar a implementação de decisões e políticas governamentais. Para outras situações, recorde-se que os autores apontam outra metáfora identificada na prática da patrulha policial (police patrol). ${ }^{3}$

Observou-se que, para a produção das narrativas securitárias em apreço, concorre uma intercomplementaridade. De um lado, a cobertura jornalística desenvolve sua competência de noticiar acontecimentos aos quais se atribuem riscos à segurança pública, ao patrimônio e à ordem tributária, despertando o interesse da opinião pública. Ela o faz acompanhando atentamente aqueles que, de outro lado, são os agentes que atualmente compõem a Força Nacional de Segurança Pública. ${ }^{4}$ Avaliamos que o noticiário jornalístico anima essa relação e adota a postura de produtor de alarmes de incêndio ao articular duas conjunturas distintas, quais sejam as que envolvem acontecimentos localizados em fronteiras nacionais e os ocorridos em favelas.

\footnotetext{
${ }^{2}$ Projeto contemplado com bolsa PQ do CNPq e, posteriormente, financiado pelo PNPD-Capes.

${ }^{3}$ Em Ciência Política o estudo da política externa reconhece que o Poder Legislativo delega ao Executivo o desenvolvimento das políticas de Estado. Nessa atividade, para denominar o tipo de controle centralizado, ativo e direto McCubbins e Schwartz (1984) desenvolveram a metáfora "patrulha policial", diferente do controle por "alarme de incêndio", menos centralizado. Como o segundo requer menos tempo, estrutura e informação, faz-se plausível supor que a cobertura jornalística - vulgarmente a mídia - também o exerça a sua maneira. Assim, há uma ação frequente de ativação do controle através desse alarme.

${ }^{4}$ Criada pela Lei n. 11.473 , de 10 de maio de 2007, dispõe sobre a cooperação no âmbito da segurança pública e envolve servidores civis e militares.
} 


\section{Comparando a cobertura local e a nacional}

A análise aqui relatada refere-se à cobertura de acontecimentos locais realizada pela mídia local, por meio do levantamento das edições de um diário fronteiriço naquelas matérias que tratam de ocorrências definidas pelos desdobramentos apontados por marcadores de texto operativos. Procedeu-se à leitura e seleção das matérias que faziam uso dos termos "periferia, fronteira, favela, Paraguai, Argentina”. O objetivo observado procurou conhecer semioticamente a especificidade representacional que o nível local concede aos acontecimentos já estandardizados pela mídia nacional. As edições dos anos de 2006-2007 do diário Gazeta do Iguaçu, de Foz do Iguaçu-PR, permitiram encontrar 2.667 matérias com pelo menos um dos marcadores. E para contrastar com o domínio hierarquizante do nível nacional sobre o local recorreu- se à comparação com os semanários nacionais IstoÉ e Época, editados na capital paulista, também nas edições dos anos 20062007, constituído por outros dois corpora, levantados a partir dos mesmos marcadores de texto, nos quais foram levantadas 41 e 88 matérias respectivamente. Veja-se a Tabela $1:^{5}$

Tabela 1 - O corpus de pesquisa (anos 2006-2007)

\begin{tabular}{l|c|c|c|c}
\hline $\begin{array}{l}\text { Marcador de texto / } \\
\text { Periódico }\end{array}$ & Gazeta do Iguaçu & IstoÉ & Época & Total \\
\hline Periferia & 183 & 16 & 31 & 230 \\
Fronteira & 1.617 & 7 & 17 & 1.641 \\
Favela & 63 & 2 & 12 & 77 \\
Paraguai & 1.777 & 3 & 3 & 1.783 \\
Argentina & 815 & 3 & 3 & 821 \\
Contextuais Periferia/Favela & - & 9 & 14 & 23 \\
Contextuais Fronteira & - & 6 & 11 & 17 \\
\hline Total & 4.455 em 2.667 & 46 em 41 & 95 em 88 & 4.596 em 2.796 \\
& matérias & matérias & matérias & matérias \\
\hline
\end{tabular}

${ }^{5} \mathrm{O}$ acesso pelo Grupo de Pesquisa Comunicação, Identidades e Fronteiras ao diário Gazeta do Iguaçu foi possível através da concessão de login e senha por seu editor, contatado por telefone em março de 2010. Ele é disponível somente para assinantes. O acesso aos semanários IstoÉ e Época encontra-se disponível online para qualquer usuário de Internet. 
O levantamento por meio dos marcadores de texto foi facilitado por sua veiculação digitalizada; pelos suportes online foi possível buscar os marcadores rapidamente e sistematizar as tarefas. Para a coleta de IstoÉ e Época disponibilizou-se, ademais dos marcadores referidos, de outros dois procedimentos. Eles levaram em consideração também o contexto. Ou seja, algumas das matérias não citavam, nominalmente, os termos "periferia, fronteira, favela"; no entanto, tomando-se em consideração a espacialidade do relato, foi possível situar os acontecimentos em tais lugares. Dessa forma, acrescentaram-se as matérias que apresentavam acontecimentos relativos a esses lugares, as quais foram referidas através de categorias denominadas "contexto favela/periferia, contexto fronteira".

Além disso, pode-se observar que a revista Época publicou quase que o dobro de matérias (88) que a revista IstoE (41) identificadas pelos marcadores discursivos "periferia, fronteira, favela", bem como os marcadores "contextual periferia/favela" e "periferia fronteira". Os semanários Época e IstoÉ coincidem apenas quando se trata dos marcadores "Argentina, Paraguai" (3 matérias cada). Essa característica aponta a preocupação com o âmbito interno da vida nacional e a escassa atenção concedida à relação com os Estados vizinhos.

De parte do diário local, a forte presença de referências a acontecimentos envolvendo o Paraguai (1.777 marcadores localizados em 2.667 matérias) é comparável com o uso do marcador Fronteira (1.617 em 2.667 matérias), sensivelmente superior à citação da Argentina (815 marcadores nas 2.667 matérias). A preocupação do diário local traduz o forte alinhamento procurado pelo Estado brasileiro com aquele país vizinho, em detrimento de um alinhamento político com o Mercosul.

Diante desse cenário, indaga-se sobre a vigência de um sistema que as mantém atreladas a um imaginário de situações recorrentes acerca da ausência de Estado, caos e violência, o qual persistiria mesmo com o fim da ideologia de segurança nacional e da Guerra Fria. O espaço fronteiriço local se faz vicário de uma cobertura jornalística que, sendo tomada como processo social de produção, circulação e consumo, tem suas relações articuladas intimamente com outras formas de produção textual realizadas por mídias nacionais sobre o cotidiano das fronteiras internacionais do Brasil.

Neste sentido, uma digressão se faz necessária. Seria possível compreender o agendamento de fronteiras internacionais na mídia 
brasileira como uma demonstração de pudor contra a promiscuidade atribuída às interações transnacionais que naquele lugar teriam sua maior expressão? $\bigcirc$ presente artigo, por meio da análise da cobertura jornalística, acaba indagando sobre a prossecução de agentes criminosos que impregna nosso noticiário. Como a reconstrução sociossemiótica pode ajudar na compreensão da questão da ambivalência significacional interposta ao cruzamento dos temas de segurança pública e jornalismo?

\section{A sociossemiótica e a abordagem do fenômeno comunicacional noticioso}

Considera-se que a sociossemiótica determina reconhecer o que há em comum entre as periferias metropolitanas (favelas) e internacionais (fronteiras) e constitui sua identidade. Enquanto espaço periférico generalizável, atribui-se a ambas a condição de zona de intermediação. Suas manifestações culturais estão inevitavelmente condicionadas por tal tipo de inserção a qual supõe, ademais, numa certa atividade de legitimação da ambivalência discursiva.

Adianta-se que os resultados do subprojeto aqui apresentados apontam para a consistência da hipótese de trabalho quando ela indica o tratamento de acontecimentos de periferias nacionais tomados como alarmes de incêndio. A ele se atenta midiaticamente apontando para os riscos que ameaçam a centralidade da vida nacional, a qual é observada na conversão das periferias em patrimônio territorial do Estado-nação. Constata-se, assim, e o artigo pretende apresentar elementos que o confirme, o pressuposto já identificado de que a mídia nacional observa prática semelhante quanto à cobertura de acontecimentos ocorridos nas periferias metropolitanas; uma prática que, circularmente, acaba por contaminar a atividade de cobertura que a mídia local fronteiriça realiza de seu próprio cotidiano.

A sociossemiótica ao analisar a conexão textual, põe em funcionamento referências explícitas em diferentes âmbitos discursivos, envolvendo a prática e a experiência. Eric Landowski (1995) considera que o passo da semiótica para a sociossemiótica envolve uma reflexão fundadora que se coloca no nível epistemológico e não apenas no metodológico ou no descritivo. A análise da cobertura jornalística sobre fronteiras a partir dessa perspectiva não requer apenas mudar o objeto de análise e avançar sobre o mero 
trabalho de conceituação descritiva, mas de repensar o regresso sociossemiótico da semiótica mesma.

Assim, o desenvolvimento metodológico na abordagem sociossemiótica é tomado como processo interpretante fundamental para identificar a dinâmica conceitual que sustenta a representação do objeto de comunicação e suas possíveis transformações. Umberto Eco se apresenta interessante quando aponta para a prática de ciência cega e a distinção entre a aplicação de processos interpretados contra processos interpretantes e seus modelos pré-definidos e replicados indistintamente. A mera comparação entre os contextos nacional e local preconiza a hipótese da cobertura jornalística (texto) diferenciada para ambos. No entanto, observações anteriores não indicam este caminho. $\mathrm{O}$ estudo das coberturas realizadas por mídias de pretendido alcance nacional tende a repetir determinadas bases (agendamento, angulação jornalística e valores-notícia) do enquadramento realizado pela cobertura de mídias de âmbito local.

A recepção da perspectiva sociossemiótica entre nós alimentou algumas vezes a expectativa de exatidões de método, muito provavelmente pela influência que a analítica goza. Já o giro semiótico, conforme Paolo Fabri (1999), reconhece que o significado sempre interessou a homens e mulheres, mas é recente (final do século 20) a reflexão coerente e sistemática. Não se trata de ruptura epistemológica, mas a consideração de que a linguagem ao ser condição de nosso pensamento ao mesmo tempo em que se lhe considera como instrumento de representação da realidade, exige procedimentos que envolvam novos conceitos a respeito da natureza do conhecimento, tanto científico quanto do senso comum. Assim, a linguagem passa a ser considerada como atividade realizadora de ações e não somente descrição de representações, como bem o sabem os políticos profissionais e lhe seguem os jornalistas. As correntes construcionistas (analíticas), responsáveis pela oposição ideias/mundo confrontam-se com a perspectiva que opõe linguagem e mundo, a qual supõe outra maneira de vincular a complexa tela formada pelo modo estratificado que temos de significar. Dessa maneira, estabelece-se uma diferença com a noção construtivista de que se pode fragmentar a complexidade da linguagem, das significações, do mundo, em unidades mínimas mediante combinações progressivas de elementos de significado e de traços de significantes para depois produzir ou reproduzir o sentido. 
A abordagem de três níveis semióticos, a saber: a. o plano temático e referencial; b. o plano narrativo e c. o plano discursivo insere-se numa vocação que é científica e empírica e que se vincula a práticas complexas de significação. Essa imersão envolve o funcionamento de sentidos e trabalha filosoficamente com as imagens de pensamento subjacentes aos textos que se conhece e que se quer analisar.

$\mathrm{O}$ que a sociossemiótica permite enfatizar e que determina reconhecer e o que há em comum entre as periferias e constitui sua identidade inevitavelmente condicionada por tal tipo de inserção, de certa forma legitimando a ambivalência discursiva. E é a ambivalência discursiva que analisamos a seguir, com alguns exemplos extraídos de um jornal local e de semanários de circulação nacional.

\section{Periferia nacional: a cobertura da multidão em deriva}

A crônica do permanente fluxo humano sobre a fronteira internacional conta com o exemplo do diário paranaense A Gazeta do Iguaçu, o qual apresenta cotidianamente o esforço de contrastar uma multidão em deriva frente à estaticidade das três centenas de milhares de habitantes locais. A singularidade de uma sociedade engendrada pelo encontro multicultural é subsumida pelo rótulo genérico de fronteira problemática. Seus cinco idiomas ativamente praticados - português, espanhol, guarani, árabe e chinês - são expressão legítima de sociedades emergentes economicamente e que agora têm reconhecida sua situação de ruptura com a plena condição periférica de um passado próximo, inaugurando pelas vias de uma aliança econômica sua aparição no cenário internacional.

Um primeiro eixo da contribuição da teoria semiótica do texto ou dos discursos refere-se particularmente aos principais parâmetros que intervém na organização estrutural dos signos textuais lato sensu.

Apresentamos a seguir um conjunto de sete matérias destacadas do diário local A Gazeta do Iguaçu e dos semanários Época e IstoÉ.

O diário apresenta na data de 18/04/2007 a matéria intitulada "Polícia Federal desmonta seis quadrilhas de contrabandistas", acompanhada da fotografia de um carregamento de caixas com a legenda "Policiais apreenderam 40 embarcações utilizadas para o contrabando". Há ainda a chamada "Mais de 280 policiais cumpriram mandatos de prisão em seis cidades do Paraná e um no Mato Grosso do Sul. 
A análise dos planos das matérias destacadas permite observar o que segue:

a) o plano temático e referencial compreende a seleção e a hierarquização de temas; a cobertura jornalística estabelece-se enquanto um lugar de saber o qual the franquia falar segundo um dado ponto de vista. Nele, a premência de controles do Estado na fronteira internacional com o Paraguai e a Argentina e a hierarquização do tema toma as lógicas de passagem como responsáveis por problemas ocorridos no ambiente metropolitano. Produz-se a refiliação da sociedade em identidades coletivas artificiais. Alguns exemplos de A Gazeta do Iguaçu nesse aspecto:

- “Apreensões da PF passam de sete toneladas"(30/06/2007).

- "Federais apreendem dez veículos de contrabandistas" (29/06/2007)

- " $\quad$ "PF apreende cinco toneladas de maconha" (29/06/2007).

A redução da tensão entre globalização e localização a aspectos mecanicamente tratados está presente na revista Época, com a matéria intitulada "Ele salva traficantes" de 31/07/06, na qual se apresenta uma liderança que negocia com traficantes numa favela carioca em favor de jovens, apresenta a exceção que faz a regra nesse tipo de noticiário:

b) o plano narrativo ou retórico trata do desenvolvimento de temas selecionados por meio da forma de atos discursivos e gêneros narrativos lato senso como situações recorrentes e articuladas de forma ambígua e que hierarquiza como semelhantes os acontecimentos relacionados à ausência de estado, caos e violência. Avançando-se na análise, percebe-se que a cobertura jornalística estabelece-se enquanto lugar de saber o qual the franquia falar segundo dado ponto de vista e as vozes oficiais mantém-se privilegiadas.

- A matéria intitulada "Em alta voltagem. O cerco a Itaipu aperta, empresas vão à Justiça e oposições se articulam no Brasil e no Paraguai" exercita a articulação entre a lógica local e o âmbito internacional, mediado pelas respectivas forças políticas. Também 
são exemplos da subordinação à lógica heteronômica as seguintes matérias do diário Gazeta do Iguaçu:

- "Medida provisória regulariza sacoleiros" (30/07/2007).

- "Itaipu binacional refuta reportagem da Istoé" (16/01/2006);

- "IstoÉ nega direito de resposta à Itaipu"(20/01/2006);

- "Itaipu refuta denúncias feitas em Veja" (06/03/2006).

c) a análise do plano discursivo produz o enquadramento do tema, orquestração das vozes que o comentam e discutem, a utilização de figuras e outras estratégias que seriam reconhecidas antecipadamente, as quais se pode apontar como autoridades legais e policiais estão apresentadas como na matéria intitulada "Polícia Federal desmonta seis quadrilhas de contrabandistas" A matéria intitulada "Os terroristas estão aqui?" mostra uma matéria de Época em que a revista entrevistou, nos Estados Unidos, aqueles a quem o governo daquele país acusa de financiar o terrorismo em nossa tríplice fronteira e afirma: "A Tríplice Fronteira é ponto de entrada de contrabando, pirataria, armas e drogas" em destaque, realizando o proposto pelo plano da expressão sincrética de um conteúdo, o qual envolve considerar os meios e linguagens de expressão, relações semióticas entre várias linguagens nas matérias jornalísticas. No nível local, essa lógica pode ser evidenciada pela presença dos seguintes títulos de A Gazeta do Iguaçu:

- "Pistoleiro mata autônomo em pizzaria" (21/01/2006);

- " "Polícia mantém ocupação na favela da Rocinha" (18/02/2006);

- "Relatório estadunidense aponta foco de terrorismo no Brasil" (03/03/2006);

- "Megatraficante do PCC vivia em Foz" (18/04/2006);

- "Bandidos lançam onda de assaltos e morte" (22/04/2006);

- "Município reivindicará indenização de laranjas" (30/06/2007);

- " $\quad$ "Estudantes são crivados de balas na periferia" (28/06/2007);

- "Transformação. Metas priorizam educação, saúde e geração de empregos” (28/06/2007).

A articulação de interesses entre favela e fronteira, terrorismo e matadores demonstra como a ambivalência produz sentidos consagrados pelo olhar nacional sobre o espaço local. 
Como início de reversão do quadro de subordinação do localismo à globalização hegemônica, um exemplo da mídia local que tende a superar o quadro estigmatizante é a matéria publicada por A Gazeta do Iguaçu em 28/04/2007 intitulada "Ato de cooperação entre Foz do Iguaçu e Salta é assinado", com uma fotografia onde dois homens assinam papeis. A chamada acrescenta: "Autoridades brasileiras e argentinas querem intercâmbio de projetos entre Foz e Salta”. A matéria aborda especificamente as ações de cooperação mútua entre o município brasileiro e o argentino, envolvendo aspectos do desenvolvimento do turismo e da cultura.

Em outra matéria de 24/04/2006 intitulada "Reduções mostram grandeza da cultura jesuítico-guarani" - ademais de outras que registravam "Autoridades argentinas pedem intervenção" (30/01/2006) e "Índios argentinos mendigam em Foz" (14/02/2006) - faz-se possível reconhecer a circulação de discursos sobre o cotidiano fronteiriço, qualificando-se como importante instrumento de construção da realidade de um grupo social. Os elementos e técnicas permitem-nos identificar como é possível superar, ainda que timidamente, os valores de estigmatização impostos à cobertura das fronteiras, ainda que se mantendo no marco estabelecido em aspectos como criminalidade, legalidade e ordem social.

No entanto, é a matéria intitulada "Militares ou políticos?" de IstoÉ de 01/02/2006 que culmina com a exploração da ambivalência, jogando um manto de ambiguidade sobre a ação de distintos agentes. Rendidas face ao que historicamente o complexo colonial estabeleceu como territórios de abandono, as redações das revistas semanais produzem a atualização das hardnews enquanto espaços plenos de circuitos da ilegalidade.

A perspectiva de imunização face à diferença é assim alimentada pela cobertura jornalística brasileira nas narrativas sobre acontecimentos ocorridos em nossas fronteiras internacionais. Reiterando o já analisado anteriormente, o plano narrativo ou retórico trata do desenvolvimento de temas como situações recorrentes e articuladas de forma ambígua. Conforme Foucault (1966): "definir em sua individualidade singular um sistema de formação é, então, caracterizar um discurso ou grupo de enunciados pela 
regularidade de uma prática". ${ }^{6}$ Auxiliando na interpretação da notável continuidade de tratamento discursivo, ele diz ainda: "não propor buscar a coerência interna dos discursos, mas buscar, a partir da regularidade de uma prática, suas condições externas de possibilidade", bem como "práticas que formam sistematicamente os objetos de que falam".?

Assim, faz-se necessário avaliar em que medida o noticiário que se faz público rege-se por suas condições internas ou busca a ampliação de sua lógica no ambiente social como é o caso da matéria intitulada "Em alta voltagem. O cerco a Itaipu aperta, empresas vão à Justiça e oposições se articulam no Brasil e no Paraguai” .

\section{Periferia metropolitana: hardnews e circuitos da ilegalidade}

A construção identitária que emerge da narrativização por meio do plano discursivo conta com alguns recursos que lhes são próprios e irrenunciáveis, ainda que seu exercício seja limitado e ainda titubeante.

A aplicação da abordagem sociossemiótica sobre fronteiras tomadas por problemáticas permite distinguir a confusão operada sobre os deslocamentos em seu espaço como problemas de nosso tempo. Entretanto, se é o contexto que estabelece uma diferenciação entre o enunciatário suposto genericamente na realização de uma cobertura realizada por um veículo de circulação nacional e aquele que se situa localmente, em que implica a realização do contraste pretendido?

É necessário estar atento para os cenários de análise do enunciatário genérico suposto para veiculação da mídia nacional nas periferias brasileiras e o de análise do enunciatário particular suposto pela veiculação da mídia local em contextos periféricos da periferia nacional (fronteiras internacionais brasileiras) e periferia metropolitana (favelas)

\footnotetext{
${ }^{6}$ No original: "definir en su individualidad singular un sistema de formación es, pues, caracterizar un discurso o un grupo de enunciados por la regularidad de una práctica". ${ }^{7}$ No original: "no proponer buscar la coherencia interna de los discursos, sino buscar, a partir de la regularidad de una práctica, sus condiciones externas de posibilidad", bem como "prácticas que forman sistemáticamente los objetos de que hablan".
} 
As revistas de circulação nacional e edição semanal não conhecem maiores condicionamentos que as determinem operar num nível de adequação às particularidades periféricas seja da nação (sociedade fronteiriça), seja de suas metrópoles (sociedades de favelados). Sua produção está padronizada para um "leitor médio" que não é conhecido nem valorizado em suas particularidades, mas no que tem em comum com outros leitores situados em distintos ambientes urbanos do Brasil.

Faz-se importante enfatizar a distinção entre cidades localizadas em fronteiras internacionais e espaços suburbanos. Prevalece nos últimos a sociabilidade que ainda guarda elementos próprios do ambiente rural, plena de familiaridades, simplicidade, debilitação de hierarquias sociais e que atua com base numa lógica inclusiva. Ambos também se diferem das comunidades de favela, nas quais a resistência à violência da hierarquia social conduz à reiteração da lógica de exclusão e que também pode ser encontrada nas sociedades localizadas em fronteiras internacionais.

Os contextos periféricos podem ainda distinguir-se pela questão étnica. No caso das fronteiras sulbrasileiras, eles conhecem o multiculturalismo que, nas bordas do Estado-nação ganha certo relevo, com seus idiomas e hábitos distintos. A presença de muçulmanos e suas mesquitas, de asiáticos e guaranis são elementos distintos à situação de incrustação das favelas na malha urbana metropolitana do Rio de Janeiro, por exemplo.

\section{Noticiário político ou publicização de tiranias privadas}

Os resultados aqui apresentados apontam para a consistência da hipótese de trabalho especificamente quanto ao tratamento de acontecimentos de periferias nacionais tomados como alarmes de incêndio. $O$ pressuposto já identificado de que a mídia nacional observa prática semelhante quanto à cobertura de acontecimentos ocorridos nas periferias metropolitanas, circularmente, acaba por contaminar a atividade de cobertura que a mídia local fronteiriça realiza de seu próprio cotidiano, corroborando o poder estandardizante da mídia nacional sobre a local. 
Caracteriza-se, dessa maneira, como o circuito se retroalimenta, produzindo a ambivalência entre acontecimentos ocorridos em locais diferentes, com causalidades diversas e que envolvem agentes distintos. Sua condição comum acaba sendo aquela articulada pela própria noticiabilidade, a qual dosa a sociedade cotidianamente com a inoculação de um alerta, fazendo recordar que algo perigoso se passa nas periferias. Pode-se presumir que, ao colocar os diferentes em condição de equivalência, há uma prática de imunização da sociedade. Essa ação ameniza o estranhamento que a equivalência entre acontecimentos díspares poderia provocar e dela resulta a ambivalência comunicacional.

Para a conjuntura em apreço concorre, de um lado, a cobertura jornalística quando desenvolve sua competência em complemento à ação de patrulha dos agentes de polícia. Midiaticamente está-se apontando para os riscos que ameaçam a centralidade da vida nacional, produzindo narrativas securitárias que teriam o poder de operar a conversão das periferias em patrimônio territorial do Estado-nação.

Conforme analisamos em Silveira (2011), o diálogo entre noções de imaginário midiático e de imaginário da cultura nacional permite aos processos comunicacionais noticiosos efetivar um controle do poder político sobre amplas camadas sociais pertencentes às periferias. Obviadas em sua concretude e contexto histórico, as periferias metropolitanas tomadas como favelas são alinhadas a outras periferias. Seu noticiário conduz ao constrangimento de um imaginário policêntrico e que se encontra segregado. E assim, a ambivalência significacional incide discursivamente em processos tão distintos como o de segurança pública, de identificação e de reconhecimento de si ou as relações internacionais.

A produção de narrativas securitárias responsáveis pela alimentação do propósito de imunização contra a diferença pode ter sua proporção avaliada ao recorrer-se à afirmação de Bernardo Sorj (2001, p.29) de que "nenhum sistema de valores sociais, no sentido do conjunto de crenças morais e normas práticas que ajudam a conduzir-se na vida social, possui um caráter coerente ou lógico”. O Brasil, nação de imigrantes, expõe desabridamente as injunções que a extensão de seus 16.885,7 quilômetros de limites geográficos 
com vizinhos sulamericanos supõe aos transeuntes, a par da condição única e comparável somente à continentalidade chinesa no que se refere ao número de tríplices fronteiras. Pelo exercício da lógica de imunização do Estado frente a sua diversidade interna, homogeinizam-se as narrativas sobre a nação cujo território foi apropriado dos aborígines e colonizado por estrangeiros. $O$ estado de exceção emerge por meio de figuras jurídico-administrativas:

A violência é múltipla e tem como fonte principal o abandono secular ou a presença mínima do Estado em regiões onde se concentram os pobres e excluídos. Essa violência é particularmente sentida pelos moradores de favelas nas grandes cidades, dominadas por quadrilhas de traficantes de drogas em guerra (e em associação delituosa) com a polícia, e nas regiões rurais mais pobres onde os fazendeiros fazem a lei (SORJ, 2001, p.34).

balizamento do tratamento concedido às periferias metropolitanas brasileiras quanto a seu rotineiro enquadramento de desvio da normalidade evoca a preocupação com a política de reconhecimento criada pelo Estado Varguista. Considerando-se a condição pós-moderna de nosso ambiente cultural, tem-se uma cobertura ocupada da produção daquilo que Fredric Jameson (1996) denominou de alegoria do centro que ocupa seu lugar cultural no centro da crise legitimatória do Estado nacional. Nesse contexto, os periféricos se igualam; fronteiriços e favelados não são diferentes, são iguais porque periféricos.

A reiteração e a continuidade de enquadramento discursivo observada na análise da cobertura jornalística das situações que envolvem acontecimentos as periferias brasileiras estabelecem uma relação entre a crônica do cotidiano fronteiriço e as mazelas da nacionalidade.

A cobertura de periferias tomadas como exotopias da nação reflete a incapacidade da mídia de referência de absorver a interpelação da visão da multidão em deriva, de um lado, e a preterição de vozes representativas da singular localidade dos três municípios articulados pela fricção da tríplice fronteira, de outro. Cristaliza-se a produção de narrativas homogêneas e inertes das múltiplas temporalidades quando compreendidas linearmente. A imunização da sociedade contra a diferença que constitui internamente o 
Estado-nação aprofunda a preterição de cidadãos denominados de sacoleiros, via de regra trabalhadores não reconhecidos pelo sistema formal. A imunização tangencia ainda a extensão social que a momentânea convergência espacial que episodicamente concentra multidões ocupadas do comércio informal em trânsito por nossas fronteiras internacionais detêm e que se desdobra internamente em distintos níveis nacionais em favor de um padrão securitário propugnado pela ordem legal e pelo desenvolvimentismo.

A incapacidade de entender que o fenômeno da globalização envolve a pluralidade de situações e, especialmente, que algumas delas se fazem palpáveis nas fronteiras internacionais, ludibria o conhecimento empírico de que a globalização é a imposição generalizada de alguns localismos que se globalizam. Argumenta Boaventura de S. Santos: "As globalizações hegemônicas são, de facto, localismos globalizados, os novos imperialismos culturais. Podemos definir globalização hegemônica como o processo através do qual um dado fenômeno ou entidade local consegue difundir-se globalmente e, ao fazê-lo, adquire a capacidade de designar um fenômeno ou uma entidade rival como local" (SANTOS, 1996, p.26-7). Essa perspectiva engolfa os particularismos próprios das periferias, fenômeno que é amplificado pelo complexo colonial próprio da formação cultural brasileira e extensivo ao senso comum imperante nas redações jornalísticas.

O efeito desorientador da proliferação desse modelo narrativo securitário coincide com a crítica de Noam Chomsky (2002) à mitologia do mercado, à manipulação exercida por interesses empresariais no agendamento informativo, ao impacto oculto que organizações antidemocráticas como a Organização Mundial do Comércio ou o FMI exercem sobre a agenda internacional, resumidos pelo título de tiranias privadas.

A conversão das fronteiras em patrimônio territorial do Estado requer considerá-las continuamente pelas garantias atinentes a um valor de depósito caucionado pela sociedade fronteiriça. $\bigcirc$ valor imobiliário que o território nacional representa para o Brasil foi a principal característica da política imperial do século 19 e mantém-se na concepção atual com vistas a assegurar a posse, o domínio e ainda o sossego das populações assentadas no centro. Os espaços 
fronteiriços aparecem assim despidos de interesse social além dos atributos securitários e com anuência midiática aos problemas de Estado. Como ironiza Eduardo Galeano (2009, p.107) ao destacar a postura de um especialista em vendas de segurança: "Nossa melhor publicidade são os noticiários da televisão".

Com a globalização observa-se a tendência da polícia de impor regimes de fronteira, os quais comprometem o que a Antropologia define simplesmente como "lógicas de passagem": a mobilidade, o ir e vir de transeuntes, os direitos e garantias individuais e a identidade dos cidadãos assegurados constitucionalmente.

A mobilidade incessante tornou-se característica da vida contemporânea. Zygmunt Bauman (2005, p.95) chega a apontar a atual "condição de terra de fronteira que caracteriza o espaço global interestatal". Acorrer aos redutos fronteiriços parece ter-se tornado uma constante que se desdobra em várias outras partes da sociedade, reproduzindo o efeito de fronteira em lugares plenificados pelo cosmopolitismo de sua sociedade, como é o caso das metrópoles e suas favelas.

Assim, a denegação da condição heterotópica própria a acontecimentos produzidos nas sociedades localizadas nas fronteiras internacionais brasileiras tem um enquadramento reiteradamente reproduzido pela mídia. Seus acontecimentos são reduzidos à lógica de um espaço territorial a mercê do julgamento da opinião pública mediante sua subordinação à lógica jurídico-administrativa do Estado-nação. Nessa condição, o tratamento noticioso de fronteiras encontra um duplo limite. Trata-se do limite experimentado enquanto espaço social de reinvenção heterogênea do espaço-tempo e também do limite enquanto borda de abandono e exceção não tolerados e passíveis de enquadramento arbitrário pela normalidade atribuída à centralidade da vida nacional. A vida nas favelas aí tem um amálgama, por meio do qual se narra a ambivalência entre o outro e o mesmo.

\section{Referências}

BAUMAN, Zigmunt. Vidas desperdiçadas. Rio de Janeiro: Zahar, 2005. 
CHOMSKY, Noam. El beneficio es lo que cuenta. Neoliberalismo y orden global. Barcelona: Crítica, 2002.

FABRI, Paolo. El giro semiótico. Barcelona: Bosch, 1999.

FOUCAULT, Michel. Las palabras y las cosas. Buenos Aires: Siglo Veinteuno, 1966.

GALEANO, Eduardo. De pernas pro ar. A escola do mundo ao avesso. Porto Alegre: L\&PM, 2009.

JAMESON, Fredric. Pós-modernismo: lógica cultural do capitalismo tardio. São Paulo: Ática, 1996.

JORNAL A GAZETA DO IGUAÇU. Foz do Iguaçú, 28 abril 2007. Disponível em: <http://www.gazeta.inf.br> Acesso em 15 maio 2010.

LANDOWSKI, Eric. Sociedad figurada: ensayos de sociosemiótica. Madri: Fondo de Cultura Económica, 1993.

McCUBBINS, Mathew D.; SCHWARTZ, Thomas. Congressional oversight overlooked: police patrols versus fire alarms. American Journal of Political Science, Malden, p. 165-179, v. 28, n. I, fev., 1984.

REVISTA ÉPOCA. São Paulo, 10 set. 2008. Disponível em:

<http://revistaepoca.globo.com/Revista/Epoca/0,,EMI56463-15223,00-

OS+TERRORISTAS+ESTAO+AQUI.html>. Acesso em: 20 jun. 2009.

REVISTA ISTOÉ. São Paulo, 01 fev. 2006. Disponível em:

$<$ http://www.istoe.com.br/reportagens/16367_EM+ALTA+VOLTAGEM+> . Acesso em:

20 jun. 2009.

SANTOS, Boaventura de S. A queda de Angelus Novus. Revista Crítica de Ciências Sociais, Coimbra, n.45, p. 5-34, maio de 1996.

SILVEIRA, A. C. M. O noticiário sob a mão forte do Estado. Segregação midiática e controle do imaginário. In: XX ENCONTRO ANUAL DA COMPÓS, 2011, Porto Alegre. Anais eletrônicos... Disponível em: < http//:www. compos.org.br/biblioteca $>$. Acesso em 24.10.2011.

SORJ, Bernard. A nova sociedade brasileira. Rio de Janeiro: Zahar, 2001. 